\title{
Preventable causes of cancer in Texas by race/ethnicity: tobacco smoking
}

\author{
Franciska J. Gudenkauf ${ }^{1,2}$, Aaron P. Thrift ${ }^{1,3}$ \\ 'Section of Epidemiology and Population Sciences, Department of Medicine, Baylor College of Medicine, Houston, TX, USA; ${ }^{2}$ University of Texas \\ Health Science Center at Houston School of Public Health, Houston, TX, USA; ${ }^{3}$ Dan L Duncan Comprehensive Cancer Center, Baylor College of \\ Medicine, Houston, TX, USA
}

\begin{abstract}
OBJECTIVES: Tobacco smoking is classified as carcinogenic to humans (International Agency for Research on Cancer Group 1). We aimed to estimate the percentage and number of incident cancer cases diagnosed in Texas in 2015 that were attributable to tobacco smoking, and we examined differences in the proportions of smoking-attributable cancers between the major racial/ ethnic subgroups of the population.
\end{abstract}

METHODS: We calculated population-attributable fractions for cancers attributable to tobacco smoking using prevalence data from the Texas Behavioral Risk Factor Surveillance System and relative risks associated with smoking status from pooled analyses of cohort studies or meta-analyses. Cancer incidence data were collected from the Texas Cancer Registry.

RESULTS: We estimated that 19,000 excess cancer cases or 18.4\% of all cancers diagnosed in 2015 in Texans aged $\geq 25$ years were caused by tobacco smoking. Males had a higher overall proportion of cancers attributable to tobacco smoking than females (male, 23.3\%, 11,993 excess cases; female, 13.5\%, 7,006 cases). Approximately $20 \%$ of cancer cases in non-Hispanic Whites and non-Hispanic Blacks were attributable to tobacco smoking compared to $12.8 \%$ among Hispanics.

CONCLUSIONS: Despite ongoing public health campaigns combatting tobacco use, this preventable behavior still contributes significantly to cancer incidence in Texas. Racial/ethnic differences in smoking prevalence and smoking-attributable cancer incidence should be considered when designing cancer prevention programs.

KEY WORDS: Population attributable fraction, Health status disparities, Risk factors, Tobacco use, Cancer

\section{INTRODUCTION}

As part of its mission, the International Agency for Research on Cancer (IARC) strives to identify causes of cancer [1]. In its Monographs on the Evaluation of Carcinogenic Risks to Humans, the IARC classified tobacco smoking as a Group 1 carcinogen, indi-

\section{Correspondence: Aaron P. Thrift}

Section of Epidemiology and Population Sciences, Department of Medicine, Baylor College of Medicine, 1 Baylor Plaza, Houston,

TX 77030-3498, USA

E-mail: aaron.thrift@bcm.edu

Received: May 28, 2021 / Accepted: Jul 13, 2021 / Published: Jul 13, 2021

This article is available from: https://e-epih.org/

(c) This is an open-access article distributed under the terms of the Creative Commons Attribution License (https://creativecommons.org/licenses/by/4.0/), which permits unrestricted use, distribution, and reproduction in any medium, provided the original work is properly cited.

(C) 2021, Korean Society of Epidemiology cating "sufficient evidence of carcinogenicity in humans [1]." Specifically, the IARC declared that tobacco smoking causes cancers of the lung, oral cavity, pharynx, nasal cavity/accessory sinuses, larynx, esophagus, stomach, pancreas, colorectum, liver, kidney (body and pelvis), ureter, urinary bladder, cervix, ovary (mucinous), and myeloid leukemia [1]. Despite aggressive public health attention and declining rates of tobacco use in the United States, smoking remains a concerning source of the burden of cancer and other chronic diseases [2]. Additionally, the smoking prevalence in the United States has historically differed among racial/ ethnic groups, suggesting a need to better understand how smoking-attributable cancers are distributed by race/ethnicity [2]. This may better inform cancer prevention while addressing cancer health inequalities.

In the current analysis, we aimed to estimate the population-attributable fractions (PAFs) and number of cancer cases diagnosed in Texas in 2015 that were attributable to tobacco smoking. Fur- 
thermore, we hypothesized that differences in PAFs would be apparent across racial/ethnic subgroups given the population diversity in Texas, so we stratified our study by race/ethnicity to expose any possible effect modification that may better guide cancer prevention efforts.

\section{MATERIALS AND METHODS}

The Texas Cancer Registry provided counts of invasive cancer cases newly diagnosed in Texas in 2015 , overall and by age group (25-34, 35-44, 45-54, 55-64, 65-74, 75-84, $\geq 85$ years), sex, and race/ethnicity (all races/ethnicities, non-Hispanic Whites, nonHispanic Blacks, Hispanics, and other races/ethnicities) [3]. Coding for cancer sites was performed using the Surveillance, Epidemiology, and End Results Site Recode International Classification of Diseases (ICD)-O-3/World Health Organization 2008 definitions [4]. This code for the lung cancer site also included bronchial cancers [4]. Ovarian mucinous cancer was specified by histology codes [5,6], and nasal cavity/accessory sinus cancers were coded using primary ICD-O-3 site codes [4,7]. Due to available risk estimates, we grouped oral cavity and pharyngeal cancers together, as well as kidney (body and pelvis) and ureteral cancers, and nasal cavity and accessory sinus cancers (Table 1).

Relative risk (RR) estimates for smoking status (current or former, relative to never smokers) were primarily derived from a pooled analysis of United States-based cohort studies examining the association of smoking with the risk of cancer mortality [8]. We elected to use these RR estimates, rather than RR estimates associated with cancer incidence, so that our findings would be both directly comparable and add to (by providing race/ethnicspecific PAFs) findings from a recent study of the overall PAF in the United States [9]. For the majority of cancer sites, there is overlap of the $95 \%$ confidence intervals in RR estimates of cancer incidence and mortality associated with smoking status. For cervical cancer and nasal cavity/accessory sinus cancer, estimates from this source were excluded; instead, estimates were obtained from a large prospective cohort study [10] and global meta-analysis [11], respectively, examining the association between smoking and risk of cancer. Table 1 shows the RR estimates used in the current study.

The Texas Behavioral Risk Factor Surveillance System (BRFSS) provided weighted prevalence estimates (weighted to demographic proportions within the population via post-stratification) [12] of current and former smoking in Texas by age group, sex, and race/ethnicity (Table 2) [13]. Current smokers were defined as having smoked 100 cigarettes in their lifetime and currently smoking some days or every day, while former smokers were defined as having smoked 100 cigarettes in their lifetime and not currently smoking [14]. The estimated latency period for cancers attributable to smoking varies widely across studies and across cancer sites [15]; however, because ranges for the latency period include 10 years for nearly all cancer sites, and for consistency across cancer sites, we estimated an average latency period of 10 years for all cancer
Table 1. Relative risks (RRs) associated with smoking by status (current vs. never-smokers, former vs. never-smokers)

\begin{tabular}{|c|c|c|c|}
\hline Cancer site & $\begin{array}{l}\text { Exposure } \\
\text { category } \\
\text { (smoker) }\end{array}$ & Males & Females \\
\hline \multirow[t]{2}{*}{ Lung, bronchus $^{1}$} & Current & 25.3 & 22.9 \\
\hline & Former & 6.8 & 6.8 \\
\hline \multirow[t]{2}{*}{ Oral cavity, pharynx ${ }^{2}$} & Current & 5.7 & 5.6 \\
\hline & Former & 1.7 & 2.2 \\
\hline \multirow[t]{2}{*}{ Larynx } & Current & 13.9 & 103.8 \\
\hline & Former & 2.4 & 11.6 \\
\hline \multirow[t]{2}{*}{ Esophagus } & Current & 3.9 & 5.1 \\
\hline & Former & 2.6 & 2.2 \\
\hline \multirow[t]{2}{*}{ Stomach } & Current & 1.9 & 1.7 \\
\hline & Former & 1.5 & $1.1^{7}$ \\
\hline \multirow[t]{2}{*}{ Pancreas } & Current & 1.6 & 1.9 \\
\hline & Former & 1.0 & 1.2 \\
\hline \multirow[t]{2}{*}{ Colorectum } & Current & 1.4 & 1.6 \\
\hline & Former & 1.2 & 1.2 \\
\hline \multirow[t]{2}{*}{ Liver } & Current & 2.3 & 1.8 \\
\hline & Former & 1.5 & $1.1^{7}$ \\
\hline \multirow[t]{2}{*}{ Kidney, renal pelvis, ureter ${ }^{3}$} & Current & 1.8 & $1.2^{7}$ \\
\hline & Former & 1.5 & $1.2^{7}$ \\
\hline \multirow[t]{2}{*}{ Urinary bladder } & Current & 3.9 & 3.9 \\
\hline & Former & 2.4 & 2.3 \\
\hline \multirow[t]{2}{*}{ Cervix } & Current & - & 1.9 \\
\hline & Former & - & 1.5 \\
\hline \multirow{2}{*}{$\begin{array}{l}\text { Ovary (mucinous; histology codes: } \\
8470,8471,8480,8481)^{4}\end{array}$} & Current & - & $1.1^{7}$ \\
\hline & Former & - & $1.1^{7}$ \\
\hline \multirow[t]{2}{*}{ Myeloid leukemia $^{5}$} & Current & 1.9 & $1.1^{7}$ \\
\hline & Former & 1.4 & $1.1^{7}$ \\
\hline \multirow{2}{*}{$\begin{array}{l}\text { Nasal cavity, accessory sinuses (primary } \\
\text { site codes: }\left(300,(310-319)^{6}\right.\end{array}$} & Current & 1.95 & 1.95 \\
\hline & Former & 1.39 & 1.39 \\
\hline
\end{tabular}

'RR for trachea, lung, bronchus.

${ }^{2} \mathrm{RR}$ for lip and oral cavity.

${ }^{3} \mathrm{RR}$ for kidney and renal pelvis.

${ }^{4}$ RR for ovary.

${ }^{5}$ RR for acute myeloid leukemia.

${ }^{6} \mathrm{RR}$ for nasal-sinuses, nasopharynx.

${ }^{7}$ The reported confidence interval includes the null value.

types [15]. Therefore, we used BRFSS prevalence data from the year 2006.

The following formula was used to calculate PAFs for each cancer type by sex, age group, and race/ethnicity: $P A F=\frac{\sum\left(p_{*} * E R R_{x}\right)}{1+\sum\left(p_{x} * E R R_{x}\right)}$, where $p_{x}$ is the proportion of the population in exposure category $x$ (current or former smoker) and $E R R_{x}$ is the excess relative risk $\left(\mathrm{RR}_{x}-1\right)$ [16]. We multiplied PAFs by incident cancer counts to determine the number of cancer cases attributable to smoking, stratified by age group, sex, and race/ethnicity. To accommodate the latency period of 10 years, we paired the prevalence data and corresponding PAFs in each age group with cancer incidence data in the age group 10 years older (e.g., 2006 prevalence data for the 
Table 2. Prevalence (\%) of tobacco smoking ${ }^{1}$ in Texans aged $\geq 18$ years in 2006 , overall and by race/ethnicity and age group

\begin{tabular}{|c|c|c|c|c|c|c|c|c|c|}
\hline \multirow[b]{2}{*}{ Variables } & \multicolumn{3}{|c|}{ Males } & \multicolumn{3}{|c|}{ Females } & \multicolumn{3}{|c|}{ Persons } \\
\hline & $\begin{array}{l}\text { Current } \\
\text { smoker }\end{array}$ & $\begin{array}{l}\text { Former } \\
\text { smoker }\end{array}$ & Both & $\begin{array}{l}\text { Current } \\
\text { smoker }\end{array}$ & $\begin{array}{l}\text { Former } \\
\text { smoker }\end{array}$ & Both & $\begin{array}{l}\text { Current } \\
\text { smoker }\end{array}$ & $\begin{array}{l}\text { Former } \\
\text { smoker }\end{array}$ & Both \\
\hline All & 20.6 & 27.3 & 47.9 & 15.6 & 16.1 & 31.7 & 18.1 & 21.7 & 39.8 \\
\hline \multicolumn{10}{|l|}{ Race/ethnicity } \\
\hline Non-Hispanic Whites & 17.3 & 32.5 & 49.8 & 17.8 & 20.5 & 38.3 & 17.6 & 26.7 & 44.3 \\
\hline Non-Hispanic Blacks & 34.3 & 15.2 & 49.5 & 20.0 & 10.4 & 30.4 & 25.6 & 12.3 & 37.9 \\
\hline Hispanics & 24.9 & 18.9 & 43.8 & 8.9 & 9.5 & 18.4 & 16.4 & 13.9 & 30.3 \\
\hline Other races/ethnicities & 20.8 & 21.0 & 41.8 & 22.8 & 11.5 & 34.3 & 21.7 & 17.0 & 38.7 \\
\hline \multicolumn{10}{|l|}{ Age (yr) } \\
\hline $18-24$ & 31.3 & 10.7 & 42.0 & 14.6 & 7.2 & 21.8 & 23.4 & 9.0 & 32.4 \\
\hline $25-34$ & 18.4 & 12.2 & 30.6 & 12.8 & 9.8 & 22.6 & 15.6 & 11.0 & 26.6 \\
\hline $35-44$ & 18.5 & 21.4 & 39.9 & 19.8 & 12.9 & 32.7 & 19.1 & 17.2 & 36.3 \\
\hline $45-54$ & 24.1 & 32.7 & 56.8 & 20.4 & 16.1 & 36.5 & 22.3 & 24.5 & 46.8 \\
\hline $55-64$ & 18.3 & 50.6 & 68.9 & 16.3 & 26.3 & 42.6 & 17.3 & 38.0 & 55.3 \\
\hline $65-74$ & 11.4 & 51.1 & 62.5 & 10.5 & 26.0 & 36.5 & 10.9 & 37.5 & 48.4 \\
\hline $75-84$ & 7.5 & 57.5 & 65.0 & 7.0 & 29.7 & 36.7 & 7.2 & 39.8 & 47.0 \\
\hline$\geq 85$ & 21.2 & 51.7 & 72.9 & 6.8 & 24.7 & 31.5 & 13.2 & 36.7 & 49.9 \\
\hline
\end{tabular}

Current smoker: every day or some days+smoked 100 cigarettes in lifetime; Former smoker: smoked 100 cigarettes in lifetime+not currently smoking.

age group of 25-34 years corresponded to 2015 cancer counts for the age group of 35-44 years). We calculated the age-weighted percentages of incident cancer cases attributable to tobacco smoking by cancer type, sex, and race/ethnicity. Finally, we added all attributable cases across all cancer sites to estimate the percentage of all incident cancers (excluding basal cell carcinoma [BCC] and squamous cell carcinoma [SCC] of the skin) diagnosed in 2015 in Texans aged $\geq 25$ years that were attributable to tobacco smoking.

\section{Ethics statement}

This study was conducted according to the guidelines laid down in the Declaration of Helsinki. All data were publically available. The research activities of this study were deemed as exempt by Baylor College of Medicine Ethics Committee as data were deidentified and aggregated. A waiver of consent was obtained because the study was a retrospective analysis and all data were aggregated and de-identified.

\section{RESULTS}

Nearly half of Texan males (47.9\%) and a third of Texan females (31.7\%) aged $\geq 18$ years in 2006 reported having ever smoked tobacco. Overall, $39.8 \%$ of Texans in 2006 were self-reported current or former smokers. The prevalence of smoking was highest in persons aged 55-64 years (55.3\%) and lowest in persons aged 25-34 years $(26.6 \%)$ (Table 2$)$. In all age groups, males had a higher prevalence of current or former smoking than females.

Non-Hispanic Whites comprised the racial/ethnic subgroup with the highest prevalence of current or former smoking at $44.3 \%$ (Table 2). Meanwhile, the prevalence of tobacco smoking was
$37.9 \%$ in non-Hispanic Blacks and 30.3\% in Hispanics. This trend persisted when stratified by sex; non-Hispanic White male (49.8\%) and non-Hispanic White female (38.3\%) had higher prevalence rates of tobacco smoking than other racial/ethnic-sex subgroups.

Excluding BCC and SCC of the skin, there were 103,408 cancer cases diagnosed in Texan adults aged $\geq 25$ years in 2015 , with 51,472 cases in males and 51,936 cases in females. Non-Hispanic Whites had the most cancers $(65,214$ cases), followed by Hispanics (22,642 cases) and non-Hispanic Blacks (12,020); the remaining cases were found in the other races/ethnicities category $(3,532$ cases). Overall, 19,000 cancer cases or $18.4 \%$ of all incident cancers (excluding BCC and SCC of the skin) diagnosed in 2015 were attributable to tobacco smoking (Table 3). Males had a higher overall proportion of cancers attributable to tobacco smoking than females (male, 23.3\%, 11,993 excess cases; female, 13.5\%, 7,006 cases). The cancer site with the highest PAF was the lung/bronchus (84.7\%), followed by the larynx (77.9\%) and esophagus (52.6\%). Males had higher site-specific PAFs than females for all cancer sites except the larynx and pancreas (excluding female-specific cancers, mucinous ovarian cancer and cervical cancer).

Stratification by racial/ethnic subgroups revealed that non-Hispanic Whites (20.2\%, 13,152 excess cases) and non-Hispanic Blacks (20.1\%, 2,416 excess cases) had higher proportions of all cancers attributable to tobacco smoking than Hispanics (12.8\%, 2,902 excess cases). Males had higher overall PAFs than females across all racial/ethnic subgroups. For non-Hispanic Whites and Hispanics, the lung/bronchus, larynx, and esophagus were the cancer sites that contributed the highest proportions of excess cases, consistent with the findings for all races/ethnicities combined. However, for non-Hispanic Blacks, the lung/bronchus, larynx, and oral cav- 


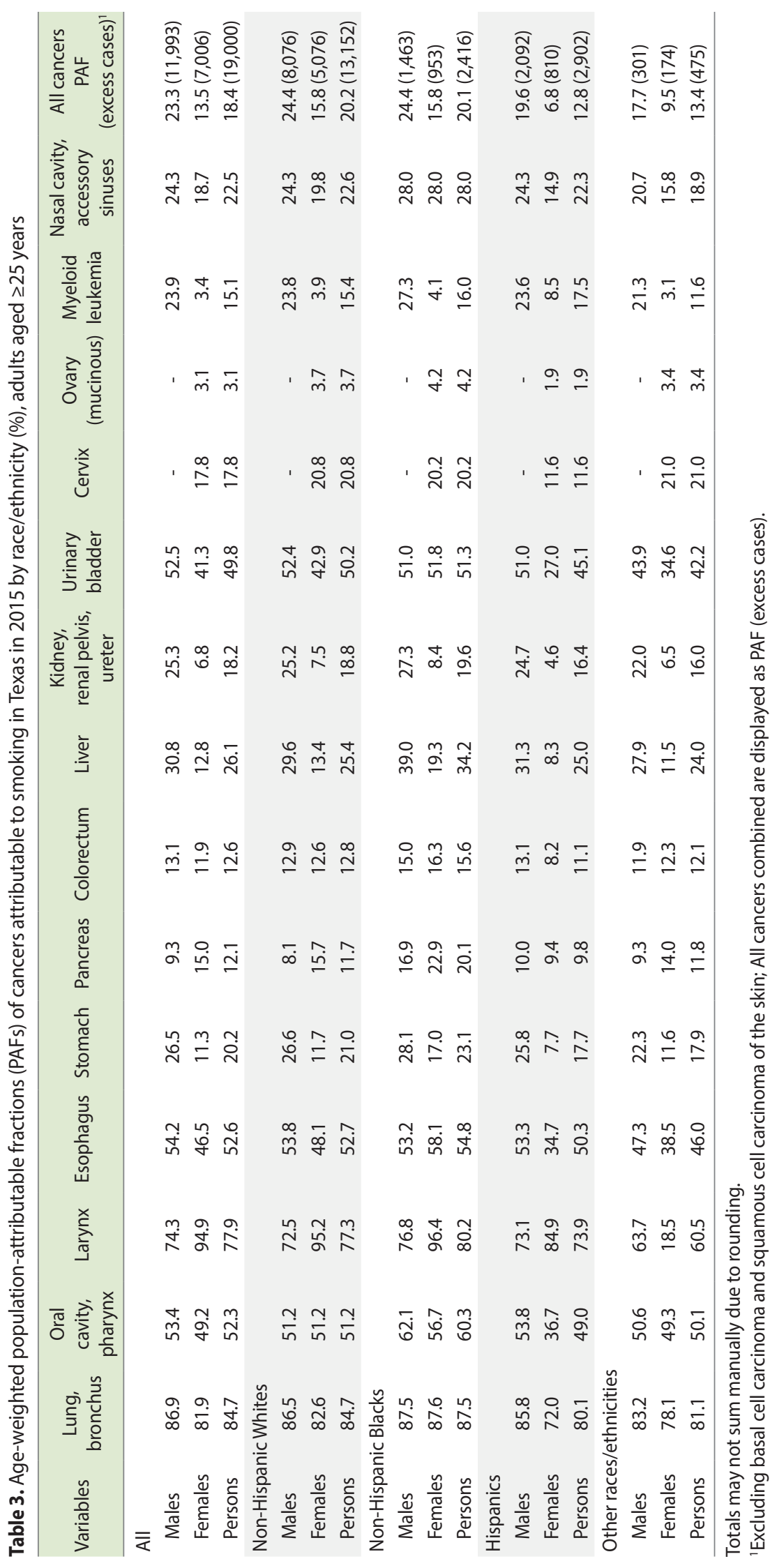


ity/pharynx had the highest site-specific PAFs. While we found that males had higher site-specific PAFs than females for all cancer sites except the larynx and pancreas (and excluding femalespecific cancers) for all races/ethnicities combined, this was not the case within racial/ethnic groups. In non-Hispanic Whites, females had higher PAFs for the larynx and pancreas sites, while the PAFs were equal between the sexes for the oral cavity/pharynx. In non-Hispanic Blacks, females had higher site-specific PAFs for the lung/bronchus, larynx, esophagus, pancreas, colorectum, and urinary bladder, and there was no sex difference for nasal cavity/ accessory sinuses. In Hispanics, the larynx was the only site with a higher PAF in females.

\section{DISCUSSION}

In this study, we estimated that in 2015 in Texans aged $\geq 25$ years, 19,000 excess cancer cases or $18.4 \%$ of all incident cancer cases (excluding BCC and SCC of the skin) were attributable to tobacco smoking. As expected, the cancer site that contributed the highest proportions of cancers was the lung/bronchus (84.7\%); tobacco smoking also caused a high fraction of laryngeal (77.9\%) and esophageal (52.6\%) cancer cases in Texas. Males (23.3\%) had a higher proportion of cancers attributable to tobacco smoking than females (13.5\%). Non-Hispanic Whites (20.2\%) and non-Hispanic Blacks (20.1\%) had higher percentages of smoking-attributable cancers than Hispanics (12.8\%).

Our findings are comparable to those of a similar PAF study conducted recently in the United States overall [9], which estimated that $19.0 \%$ of cancers (excluding non-melanoma skin cancers) were attributable to tobacco smoking in the United States in 2014 in persons aged $\geq 30$ years. However, our results and the United States-wide results are notably higher than studies conducted in other countries; in Australia in 2010 [16], 13.3\% of all cancers were found to be attributable to tobacco smoking, while in the United Kingdom in 2015 [17], 15.1\% of all cancers were due to tobacco smoking. This may be a reflection of differences in study methodology, estimates of smoking prevalence, and sources used for RR estimates. Nonetheless, these data suggest that at least 1 in 8 cancer cases are attributable to tobacco smoking in Western populations. By sex, we found a higher percentage of smoking-attributable cancers in males $(23.3 \%)$ than in females $(13.5 \%)$, a pattern consistent with the studies conducted in the United States overall (male, 23.6\%; female, 14.5\%) [9], Australia (male, 15.8\%; female, 10.0\%) [16], and the United Kingdom (male, 17.7\%; female, 12.4\%) [17].

Our analysis exposes differences in PAFs across major racial/ ethnic subgroups of the population, with greater proportions of smoking-attributable cancers in non-Hispanic Whites (20.2\%) and non-Hispanic Blacks (20.1\%) than in Hispanics (12.8\%). The higher prevalence rates of current or former smoking in non-Hispanic Whites (44.3\%) and non-Hispanic Blacks (37.9\%) than in Hispanics (30.3\%) likely contributed to the higher PAFs in nonHispanic Whites and non-Hispanic Blacks. However, it should be noted that while the overall PAFs for non-Hispanic Whites and
non-Hispanic Blacks were nearly equal, the prevalence of smoking in non-Hispanic Whites was about 1.17-fold higher than in nonHispanic Blacks. This may suggest that a greater proportion of cancers caused by factors other than smoking contributed to the denominator of overall cancer incidence in non-Hispanic Whites, thus diluting the overall PAF to an estimate that is lower than expected based solely on the contribution of smoking prevalence.

The analysis of site-specific PAFs revealed that the lung/bronchus (84.7\%), larynx (77.9\%), and esophagus (52.6\%) sites contributed the highest fractions of smoking-attributable cancers in Texas (all sexes, all races/ethnicities). Studies from the United States overall in 2014 (lung, 81.7\%; larynx, 73.8\%; esophagus, 50.0\%) [9], Australia in 2010 (lung, 79.6\%; larynx, 77\%; esophagus, 60\%) [16], and the United Kingdom in 2010 (results not reported for all persons, only reported by sex) [18] also reported these same 3 sites as the top contributors to cancer incidence, with similar magnitudes of PAFs. However, it should be noted that some of these studies used different methodologies to derive PAFs for lung cancer, so PAFs may not be directly comparable $[16,18]$. These findings further emphasize that tobacco smoking serves as an important risk factor, especially for cancers of the lung, larynx, and esophagus.

There are several limitations to our study. First, we primarily derived RR estimates from a pooled analysis of cohort studies, which provided RRs for cancer mortality for persons aged $\geq 55$ years instead of cancer incidence [8]. While it can be argued that estimates based on cancer incidence instead of mortality would have been more appropriate, we elected to reference the same source as a similar study [9] to ensure comparability of findings, which we consider a strength of this study. Additionally, we used prevalence estimates for self-reported current and former smoking, which were defined as having smoked 100 cigarettes in one's lifetime and currently smoking some/every day(s) versus not, respectively [14]. However, it is known that smoking has a cumulative effect on cancer risk based on the amount and period of time smoked [16], which is traditionally denoted by pack-years. Thus, even within each of our categories for current smokers and former smokers, individuals would likely have differences in risk due to differences in pack-years smoked. Therefore, perhaps a more robust study could use prevalence data based on pack-years and RR estimates based on dose-response by pack-years, although - to the best of our knowledge-this type of surveillance and comprehensive risk assessment is currently unavailable. Further, this complexity has stimulated the use of different methods to calculate PAFs for lung cancer in other studies, which presumably bypass these shortcomings $[16,18]$. However, we maintained standard methods and formulae for all cancer sites when calculating PAFs. Also, we assumed a latency period of 10 years between exposure and outcome, although the latency periods are difficult to measure and likely differ by cancer site [15]. Lastly, we caution against using the other races/ethnicities category to draw inferences about racial/ethnic groups not specifically analyzed in this study, as this group was small when stratified and may not be representative of other racial/ethnic identities. 
In summary, we estimated that $18.4 \%$ of all cancers $(19,000$ excess cancer cases) diagnosed in Texas in 2015 were attributable to tobacco smoking. Further, non-Hispanic Whites (20.2\%) and nonHispanic Blacks (20.1\%) had higher percentages of smoking-attributable cancers than Hispanics (12.8\%). In response to the high burden of cancers caused by tobacco smoking, public health campaigns combatting tobacco use should continue to stress the causal relationship between smoking and cancer, while also directing attention toward racial/ethnic differences, which may help in tailoring cancer prevention efforts more appropriately.

\section{CONFLICT OF INTEREST}

The authors have no conflicts of interest to declare for this study.

\section{FUNDING}

This research came from internal funds from Baylor College of Medicine.

\section{ACKNOWLEDGEMENTS}

None.

\section{AUTHOR CONTRIBUTIONS}

Conceptualization: APT. Data curation: FJG, APT. Formal analysis: FJG. Funding acquisition: APT. Methodology: FJG, APT. Project administration: APT. Visualization: FJG. Writing - original draft: FJG, APT. Writing - review \& editing: FJG, APT.

\section{ORCID}

Franciska J. Gudenkauf: https://orcid.org/0000-0002-7463-8934; Aaron P. Thrift: https://orcid.org/0000-0002-0084-5308

\section{REFERENCES}

1. International Agency for Research on Cancer. Personal habits and indoor combustions. Volume $100 \mathrm{E}$ : a review of human carcinogens; 2012 [cited 2021 May 1]. Available from: https://monographs. iarc.who.int/wp-content/uploads/2018/06/mono100E.pdf.

2. Wang TW, Asman K, Gentzke AS, Cullen KA, Holder-Hayes E, Reyes-Guzman C, et al. Tobacco product use among adults - United States, 2017. MMWR Morb Mortal Wkly Rep 2018;67:12251232.

3. Texas Department of State Health Services. Welcome to the Texas Cancer Registry [cited 2021 May 1]. Available from: https://www. dshs.texas.gov/tcr/.
4. Surveillance, Epidemiology, and End Results Program. Site recode ICD-0-3/WHO 2008 definition [cited 2019 Feb 7]. Available from: https://seer.cancer.gov/siterecode/icdo3_dwhoheme/index.html.

5. Melamed A, Keating NL, Clemmer JT, Bregar AJ, Wright JD, Boruta DM, et al. Laparoscopic staging for apparent stage I epithelial ovarian cancer. Am J Obstet Gynecol 2017;216:50.e1-50.e12.

6. International Association of Cancer Registries. International classification of diseases for oncology (ICD-O) [cited 2019 Feb 7]. Available from: http://www.iacr.com.fr/index.php?option $=$ com content $\&$ view $=$ category\&layout $=$ blog\&id $=100 \&$ Itemid $=577$.

7. SEER Training Modules, National Cancer Institute. ICD-O-3 site codes [cited 2019 Feb 7]. Available from: https://training.seer. cancer.gov/head-neck/abstract-code-stage/codes.html.

8. Carter BD, Abnet CC, Feskanich D, Freedman ND, Hartge P, Lewis $\mathrm{CE}$, et al. Smoking and mortality--beyond established causes. N Engl J Med 2015;372:631-640.

9. Islami F, Goding Sauer A, Miller KD, Siegel RL, Fedewa SA, Jacobs EJ, et al. Proportion and number of cancer cases and deaths attributable to potentially modifiable risk factors in the United States. CA Cancer J Clin 2018;68:31-54.

10. Roura E, Castellsagué X, Pawlita M, Travier N, Waterboer T, Margall $\mathrm{N}$, et al. Smoking as a major risk factor for cervical cancer and pre-cancer: results from the EPIC cohort. Int J Cancer 2014; 135:453-466.

11. Gandini S, Botteri E, Iodice S, Boniol M, Lowenfels AB, Maisonneuve $\mathrm{P}$, et al. Tobacco smoking and cancer: a meta-analysis. Int J Cancer 2008;122:155-164.

12. Centers for Disease Control and Prevention. BRFSS frequently asked questions (FAQs) [cited 2019 Feb 7]. Available from: https://www.cdc.gov/brfss/about/brfss_faq.htm.

13. Texas Department of State Health Services. Texas Behavioral Risk Factor Surveillance System; 2016 [cited 2019 Feb 7]. Available from: https://dshs.texas.gov/chs/brfss/default.shtm.

14. Texas Department of State Health Services. Texas health data: Behavioral Risk Factor Surveillance System (BRFSS) [cited 2019 Mar 28]. Available from: http://healthdata.dshs.texas.gov/CommunitySurveys/BRFSS.

15. Poirier AE, Grundy A, Khandwala F, Tamminen S, Friedenreich $\mathrm{CM}$, Brenner DR. Cancer incidence attributable to tobacco in Alberta, Canada, in 2012. CMAJ Open 2016;4:E578-E587.

16. Pandeya N, Wilson LF, Bain CJ, Martin KL, Webb PM, Whiteman DC. Cancers in Australia in 2010 attributable to tobacco smoke. Aust N Z J Public Health 2015;39:464-470.

17. Brown KF, Rumgay H, Dunlop C, Ryan M, Quartly F, Cox A, et al. The fraction of cancer attributable to modifiable risk factors in England, Wales, Scotland, Northern Ireland, and the United Kingdom in 2015. Br J Cancer 2018;118:1130-1141.

18. Parkin DM. 2. Tobacco-attributable cancer burden in the UK in 2010. Br J Cancer.2011;105(Suppl 2):S6-S13. 